\title{
Identifying Conservation and Restoration Priorities for Saproxylic and Old-Growth Forest Species: A Case Study in Switzerland
}

\author{
Thibault Lachat · Rita Bütler
}

Received: 25 August 2008/Accepted: 12 January 2009/Published online: 14 February 2009

(C) Springer Science+Business Media, LLC 2009

\begin{abstract}
Saproxylic (dead-wood-associated) and oldgrowth species are among the most threatened species in European forest ecosystems, as they are susceptible to intensive forest management. Identifying areas with particular relevant features of biodiversity is of prime concern when developing species conservation and habitat restoration strategies and in optimizing resource investments. We present an approach to identify regional conservation and restoration priorities even if knowledge on species distribution is weak, such as for saproxylic and old-growth species in Switzerland. Habitat suitability maps were modeled for an expert-based selection of 55 focal species, using an ecological niche factor analyses (ENFA). All the maps were then overlaid, in order to identify potential species' hotspots for different species groups of the 55 focal species (e.g., birds, fungi, red-listed species). We found that hotspots for various species groups did not
\end{abstract}

T. Lachat $(\square)$

Swiss Federal Institute for Forest, Snow and Landscape

Research, Zürcherstr. 111, 8903 Birmensdorf, Switzerland

e-mail: thibault.lachat@wsl.ch

T. Lachat

ENAC GECOS (Laboratory of Ecosystem Management), Swiss Federal Institute of Technology Lausanne, Bâtiment GR,

Station 2, 1015 Lausanne, Switzerland

R. Bütler

ENAC ECOS (Laboratory of Ecological Systems), Swiss Federal Institute of Technology Lausanne, Bâtiment GR, Station 2, 1015

Lausanne, Switzerland

R. Bütler

Swiss Federal Institute for Forest, Snow and Landscape

Research, Case postale 96, c/o EPFL, 1015 Lausanne,

Switzerland correspond. Our results indicate that an approach based on "richness hotspots" may fail to conserve specific species groups. We hence recommend defining a biodiversity conservation strategy prior to implementing conservation/ restoration efforts in specific regions. The conservation priority setting of the five biogeographical regions in Switzerland, however, did not differ when different hotspot definitions were applied. This observation emphasizes that the chosen method is robust. Since the ENFA needs only presence data, this species prediction method seems to be useful for any situation where the species distribution is poorly known and/or absence data are lacking. In order to identify priorities for either conservation or restoration efforts, we recommend a method based on presence data only, because absence data may reflect factors unrelated to species presence.

Keywords Dead wood - Ecological niche factor analysis - Hotspots - Old-growth forest species . Saproxylic species $\cdot$ Swiss forests

Old-growth and dead-wood-associated (saproxylic) species are among the most threatened in European temperate forest ecosystems (Grove 2002). They may survive in a suboptimal habitat (low resource availability), such as intensively managed forest landscapes, and often their distribution is poorly known. Effective conservation of species in these circumstances is not an easy task. In this paper, we present and discuss an approach to locate potential species' richness hotspots and to identify conservation and restoration priorities for cases where knowledge on species distribution is weak and absence data are lacking. 
In forest ecosystems, dead wood and other characteristic old-growth structures play a key role in biodiversity. It has been estimated that the number of saproxylic beetle species substantially outnumber the sum of all the world's species of mammals, birds, reptiles, and amphibians (Parker 1982). For example, $56 \%$ of all German forest beetle species are associated with dead wood (Köhler 2000). About 40005000 saproxylic species live in Switzerland, i.e., $20 \%$ of all forest-dwelling species. Most saproxylic species are also associated with old-growth forests, since dead wood is one of the characteristic features of such a habitat.

Many European studies have demonstrated the susceptibility of saproxylic and old-growth forest species to intensive forest management practices and forest fragmentation (e.g., Ås 1993; Komonen and others 2000; Grove 2002). Saproxylic insects comprise a disproportionately large percentage of nationally rare and threatened species (Grove 2002).

The conservation of saproxylic and old-growth forest species has become an issue in Switzerland since biodiversity conservation is one of the five key objectives of the Swiss National Forest Programme (SNFP 2003). Swiss alpine forests average $19.5 \mathrm{~m}^{3} \mathrm{ha}^{-1}$ of dead wood, which is relatively high compared to intensively managed forests. There is, however, a severe lack of dead wood in managed lowland forests (4.9 $\mathrm{m}^{3} \mathrm{ha}^{-1}$ ) (Brassel and Brändli 1999). Comparatively, in European natural forests, dead-wood amounts vary between 20 and $250 \mathrm{~m}^{3} \mathrm{ha}^{-1}$ (Korpel 1995). Old-growth forests are also rare in Switzerland. Forests in the age class of 180 years and older represent $\leq 4 \%$ of the forested area with the exception of the Alps, where they reach 13\% (Bütler and others 2006). Financial support for forest owners acting to conserve or restore dead-wood habitat is part of the national forest policy. Hence, a question of particular concern is where to set conservation and restoration priorities if the number of saproxylic species conserved has to be maximized with the minimum financial sacrifice (Margules and Pressey 2000). Ecological restoration has been defined as the process of repairing damage caused by humans to the diversity and dynamics of indigenous ecosystems. In Switzerland, where dead wood is heterogeneously distributed across landscapes, both conservation and restoration efforts for saproxylics may be needed.

From the early 1980s onward, conservationists have recognized the importance of regional concentrations of species with special ecological characteristics (hotspots) for identifying sites for biodiversity conservation (e.g., Myers 1988; Prendergast and others 1993; Myers and others 2000). Definitions of "hotspot" in the literature vary considerably (e.g., Reid 1998; Gjerde and others 2004) but can be broadly defined as an area with greater species richness compared to surrounding areas. Maps of biodiversity hotspots based on species inventories have often been used to identify conservation priorities (e.g., Myers and others 2000; Roberts and others 2002). Ideally, all available species-based information should be incorporated into regional conservation assessments (Jaarsveld and others 1998). However, the species distribution must be well known and systematic samplings are prerequisites for a meaningful identification of hotspots. This limits the number of species that can be considered. In Switzerland, the distribution of most saproxylic and old-growth species is relatively poorly known and available datasets are insufficient. Furthermore, due to forest habitat deterioration in large parts of Switzerland (especially in the lowlands), the surviving species often live in suboptimal conditions. The classic hotspot approach, based on species inventories, would therefore fail to identify regions with a high species potential after habitat restoration efforts. Hence, an approach for dealing with poorly known species distribution and enabling the setting of priorities, with regard to where to deploy conservation and restoration efforts, is needed.

In this paper, we combined an expert-based approach to select focal species (sensu Lambeck 1997) with modeling and overlaying habitat suitability (HS) maps for all the considered species. The overlaid maps of the potential distribution of focal species were then used to compare different regions' potentials for high biodiversity and to decide where conservation or restoration efforts may be worth undertaking.

The overall goal of this study was to establish guidelines for conserving saproxylic and old-growth forest species in Swiss forests. This paper aims (i) to identify potential hotspots for saproxylic and old-growth forest species in Switzerland, (ii) to investigate how different selections of species from a pre-established list affect the location of potential hotspots, and (iii) to discuss the usefulness of the chosen approach consisting of summing several species prediction maps for conservation/restoration priority setting. To the best of our knowledge, our work is the first to model potential hotspots of saproxylic and old-growth forest species groups for habitat conservation and restoration aims.

\section{Methods}

\section{Study Site}

This research was conducted in Switzerland, which is situated in the central part of Europe $\left(47^{\circ} \mathrm{N}\right.$ and $\left.8^{\circ} \mathrm{E}\right)$. Switzerland has a total surface area of $40,000 \mathrm{~km}^{2}$ and consists essentially of two mountain chains with a westeast orientation: the Jura in the north (highest peak in 
Switzerland, $1607 \mathrm{~m}$ a.s.l.) and the Alps in the south (highest peak in Switzerland, $4634 \mathrm{~m}$ ). A lowland corridor, $50-100 \mathrm{~km}$ wide, generally referred to as the Central Plateau and ranging from about 360 to $900 \mathrm{~m}$ a.s.l., separates the two mountain areas. Switzerland is divided into five biogeographical regions (Fig. 1a): Jura, Central Plateau, Pre-Alps, Alps, and Southern Alps (from the north to the south). We used this classification and mapped it on a
Fig. 1 Maps of potential hotspots of saproxylic and oldgrowth forest species in Switzerland for different species groups. a Biogeographical regions. From dark gray to white: Jura, Central Plateau, Pre-Alps, Alps, Southern Alps. b-j Circles show hotspot patches larger than $10 \mathrm{~km}^{2}$
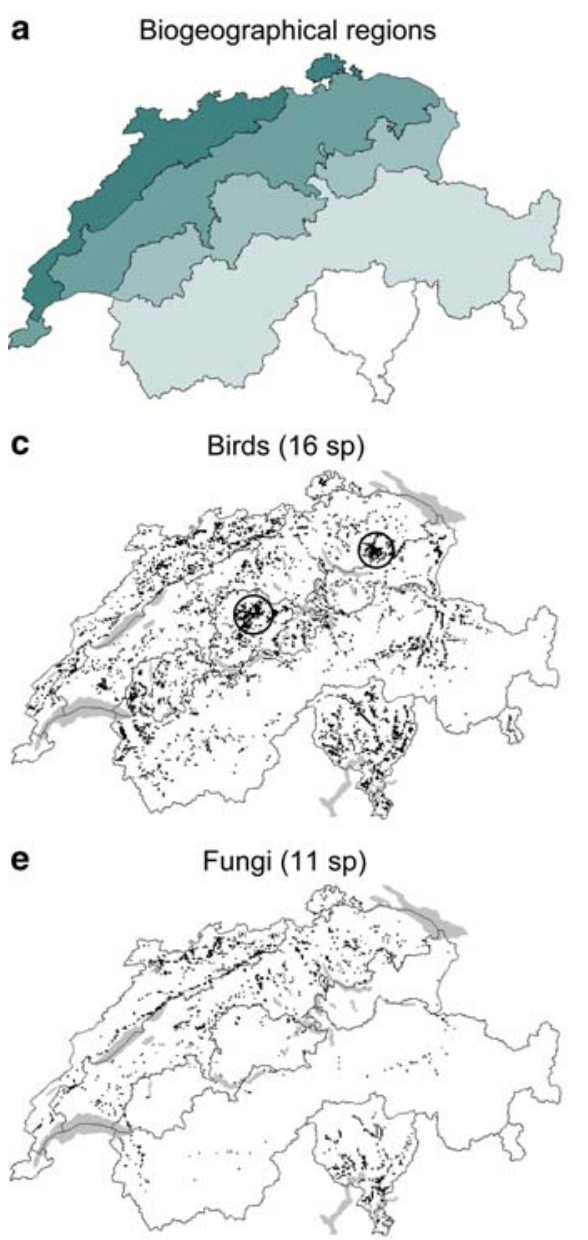

g Species on broadleaves (20 sp)

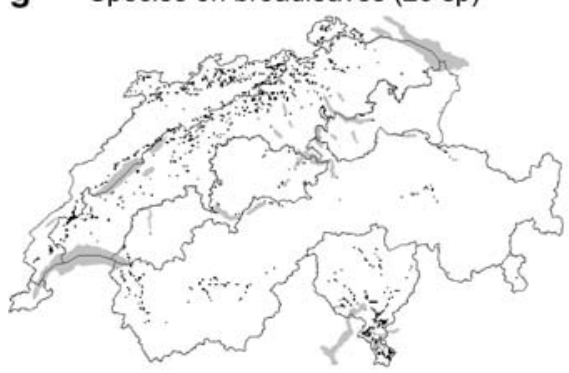

i Red-listed species (14 sp)

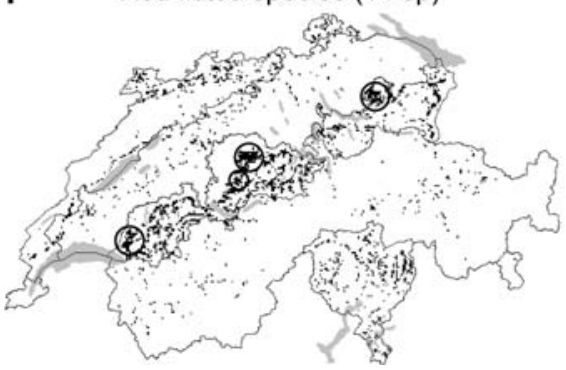

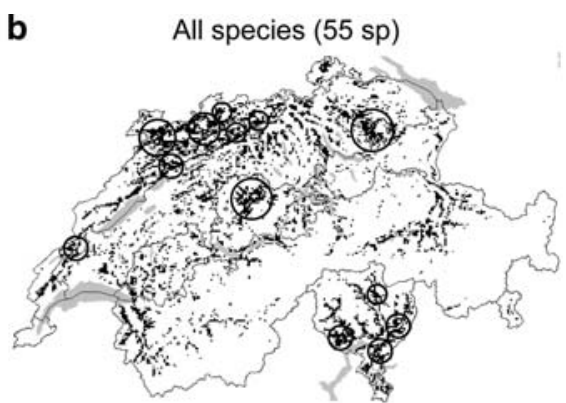

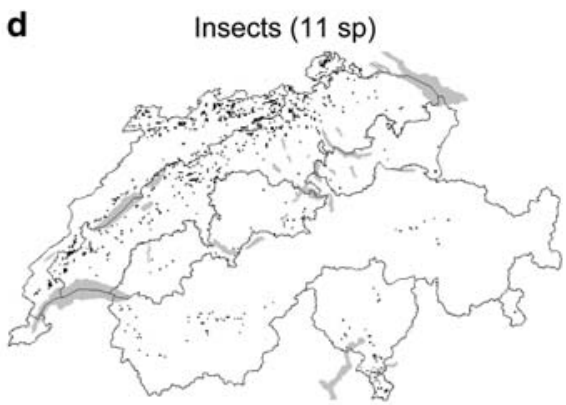

f Thermophilous species (11 sp)

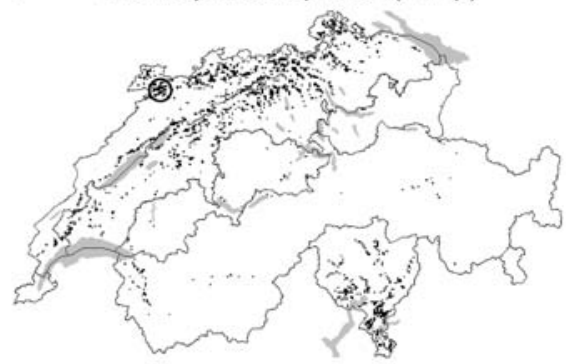

h Species on conifers (12 sp)

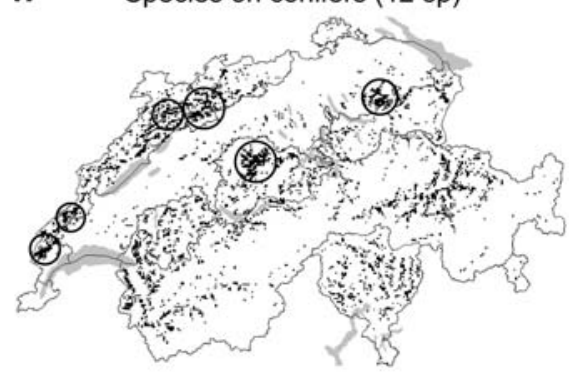

j Species in Annex EU (12 sp)

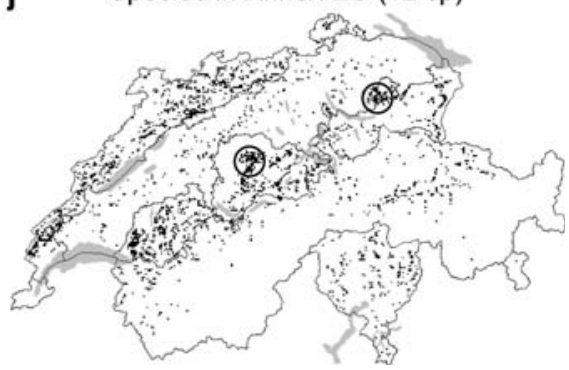


regular grid based on the Swiss Coordinate System (plane projection). The cell size was set at $1 \mathrm{~km}^{2}$.

Forests cover 1.2 million ha in Switzerland, representing about $30 \%$ of the country's total surface area (SFSO 2001). Swiss forests can be classified into six main forest communities: (i) beech forests, (ii) silver fir-beech forests, (iii) other broadleaf forests, (iv) spruce-silver fir forests, (v) spruce forests/larch-Swiss stone pine forests, and (vi) pine forests (SAEFL 1999).

\section{Species Selection}

The distribution of saproxylic and old-growth species in Switzerland is relatively poorly known, since few systematic inventories have been addressed at the national level. Therefore, we focused on a selection of species for which both the quantity and the quality of the available distribution data were sufficient (e.g., $>20$ observation points throughout Switzerland and observations after 1950). We compiled a list of saproxylic and old-growth forest species that are of conservation concern in Switzerland based on experts' recommendations. At least two highly experienced specialists in each considered species group (mammals, birds, amphibians and reptiles, insects, mollusks, fungi, and lichens) were asked independently to select priority species according to specific ecological and geographical nonexclusive criteria. These criteria referred to the protection status, habitat preference, and geographical distribution of the species. In order to limit bias, which may result from the focal species approach, the final selection, for each species group, had (i) to include protected and unprotected species, (ii) to include both species showing a preference for broadleaved and species preferring for coniferous forest, and (iii) to cover altogether all of the five biogeographical regions. Fifty-five saproxylic and oldgrowth species from experts' lists were included in this study (Appendix: Table 2). Comparatively better-known taxonomic groups (mammals, birds, amphibians, reptiles, and mollusks) included relatively more species in the final selection than groups where knowledge is still scarce (insects, fungi, and lichens).

In order to test how different selections of species from this pre-established list influence the location of hotspots, we defined nine species groups of saproxylic and oldgrowth species: all species (55 spp.), birds (16 spp.), insects (11 spp.), fungi (11 spp.), thermophilous species (11 spp.), species living on broadleaves only (20 spp.), species living on conifers only (12 spp.), red-listed species (14 spp.), and species belonging to Annex I (2003) of the European birds directive and Annex II (2003) of the European habitat directive (12 spp.). The species of these two annexes are of special concern to Europe and are referred to as Annex EU hereafter. Red-listed species include species coded as vulnerable (VU) or endangered (EN) in the Swiss red lists. No insects were included in the red-listed species group, because such a list does not yet exist for dead-wooddependent insects in Switzerland. Any species might belong to more than one defined species groups.

Distribution data on the target species of mammals, amphibians, reptiles, mollusks, and insects were available from the Swiss Centre of Cartography of Fauna (www. cscf.ch), bird records were supplied by the Swiss Ornithological Institute (www.vogelwarte.ch), and fungi and lichen data were obtained from the Swiss Federal Institute for Forest, Snow and Landscape Research (WSL; www. swissfungi.ch, www.swisslichens.ch).

\section{Prediction of Habitat Suitability}

Studies use a variety of approaches to predict modeling habitat distributions (for a review see Guisan and Zimmermann 2000; Ferrier and Guisan 2006). However, for many species, these largely statistical approaches are not feasible due to a lack of absence data (Tole 2006). True absence data require proof that the species is really not present in the area, whereas in presence data sets, only positive observations of species are registered. In most species distribution databases in Switzerland, absence data are not available. Furthermore, for most cryptic or rare species, in particular, for many saproxylic species, available data are incomplete. The ecological niche factor analysis (ENFA; Hirzel and others 2002) is an approach recommended to model HS in cases without absence data. ENFA is a method based on a comparison between the environmental niche of the species (part of the study area where the species is present) and the environmental characteristics of the entire study area (stored as GIS layers), which we call the ecogeographical variables (for details see Hirzel and others 2002). Extending these statistics to a larger set of variables directly leads to Hutchinson's (1957) concept of the ecological niche, defined as a hypervolume in the multidimensional space of ecogeographical variables within which a species can maintain a viable population (Hutchinson 1957; Begon and others 1996).

We calculated HS maps for each species (using 'Biomapper' Version 3.1, a freely available, integrated mapping and statistical software program; http://www. unil.ch/biomapper). Biotic effects (inter- and intraspecific competition, rates of extinction and colonization) were not incorporated into the assessment.

\section{Model Evaluation}

The validation procedure of the ENFA models is included in Biomapper. It is performed by a jackknife cross-validation 
process (Fielding and Bell 1997; Boyce and others 2002), partitioning each species data set (Reutter and others 2003). This method splits the species data into a number of sets $(k)$ and then uses all but one of these sets to calibrate the model and the remaining set to validate it. This procedure is repeated $k$ times, each time leaving out another partition of the data (Hirzel and others 2006). We used $k=10$ for species with more than 100 observations and $k=5$ for species with less than 100 observations (Huberty's rule). This process resulted in $k$ different HS maps for each species. The comparison of these maps provided an assessment of their predictive power. For evaluation of each species map, the suitability index was categorized into four equal-sized bins $(0-25,25-50$, 50-75, and 75-100). Each bin $i$ covered some proportion of the total study area $\left(A_{i}\right)$ and contained some proportion of the validation points $\left(N_{i}\right)$. The area-adjusted frequency (AAF) for each bin was computed as $\mathrm{AAF}=N_{i} / A_{i}$. Examination of the area-adjusted frequency across the range of HS values provided a measure of the model's performance. For a model with good predictive power, the AAF should be $<1$ for an unsuitable habitat and $>1$ for a suitable habitat, with a monotonic increase in between. The monotonicity of the curve was measured with a Spearman rank correlation between AAF and the HS and is called the Boyce index (B) (Boyce and others 2002; Hirzel and others 2006). It varies between -1 and 1 , a perfect model having a $B=1$.

To identify hotspots of saproxylic and old-growth forest species, we finally considered areas with an HS $<50 \%$ (arbitrary cutoff value) as unsuitable habitats and the remaining areas as suitable for species with all AAF curves above the 1:1 line (random distribution) at the threshold (HS $=50 \%$ ) (Hirzel and others 2006). In the other cases (not all AAF curves are situated above the 1:1 line), we used the point where the lowest of the AAF curves cut the 1:1 line as the threshold, thus separating the areas where the species is found either more or less frequently than expected by chance.

\section{Input Variables}

A cell grid of $1 \mathrm{~km}^{2}$ was considered occupied if at least one observation was known. Input variables for the selected taxa consisted of at least 20 occupied cell grids (only presence data are required). Twenty variables, derived from governmental databases, were used as ecogeographical variables for the model. These variables are mostly coarse climatic and topographic variables which generally influence the occurrence of species. Only few forest characteristics were included (Appendix: Table 3). Our aim was to model potential biodiversity hotspots for saproxylic and old-growth species under the assumption that dead wood is not a limiting factor for species presence; this way, all possible hotspots were determined. The current amounts of dead wood in many parts of Switzerland are lower than what could be expected in the frame of conservation programs or in a natural forest, and they negatively affect the distribution of saproxylic species. Consequently, we did not include dead wood as an explanatory variable in the model, and as a result, we were able to highlight valuable regions for both restoration and conservation actions.

As ENFA requires normally distributed data, all environmental layers were normalized through the 'box-cox' algorithm (Sokal and Rohlf 1981). Even though several variables did not recover normality after the applied process, we still ran the ENFA, because it is not overly sensitive to such violation (for mathematical details see Hirzel and others 2002).

\section{Potential Hotspots of Saproxylic and Old-Growth Forest Species}

We overlaid the HS maps (suitable/not suitable) of the species of each group to highlight potential hotspots. Since biodiversity is not evenly distributed across landscapes (Gaston 2000), we defined hotspots as areas (in our case, every grid cell of $1 \mathrm{~km}^{2}$ ), where the number of overlaid species was at least as high as one-half or two-thirds of the regional maximum species richness. The regional maximum species richness was determined by counting the number of species (of 55) that are potentially present in each biogeographical region (from 5 to 32 species). These hotspots are referred to as either "hotspot(1/2 richness)" or "hotspot(2/3 richness)" and were used to evaluate the robustness of our approach. Hotspots such as those defined in this study can be classified as either "richness hotspots" (hotspots based on the most species-rich plots) or "rarity hotspots" (plots with the highest number of rare species) (Tardif and DesGranges 1998).

We used two approaches to highlight conservation/restoration priorities in each of the five biogeographical regions. First, we calculated the forest surface (as hectares and percentages) per region that is, according to our definitions, classified as a hotspot. Second, we looked for hotspot patches. A patch was defined as a cluster of cells, each with a proportion of hotspots $>50 \%$ within a $5-\mathrm{km}$ radius (value arbitrarily chosen). This analysis was performed by the Biomapper's module Circan with the option "frequency of occurrence." Each square kilometer was individually considered as the center of an integration circular area with a radius of $5 \mathrm{~km}$. This radius was adapted to the small scale of the Swiss forest. Only hotspot patches larger than $10 \mathrm{~km}^{2}$ were highlighted with a circle on the maps (see Figs. 1 and 2). 


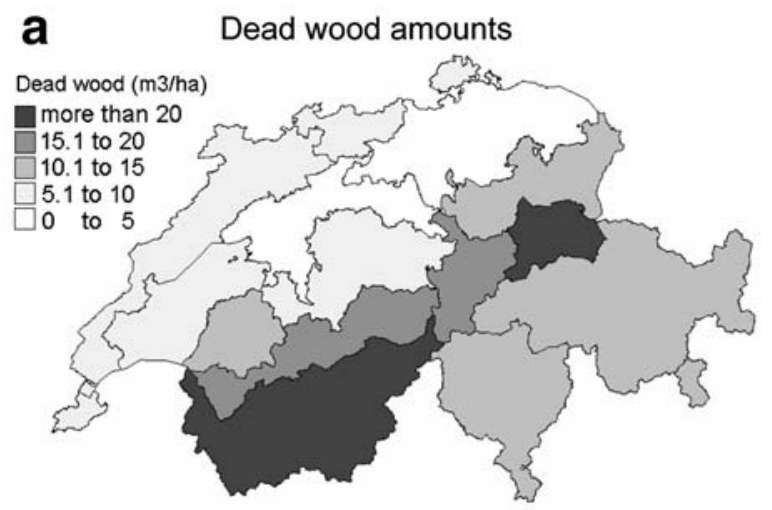

b All saproxylic species (hotspot patches $>10 \mathrm{~km}^{2}$ )
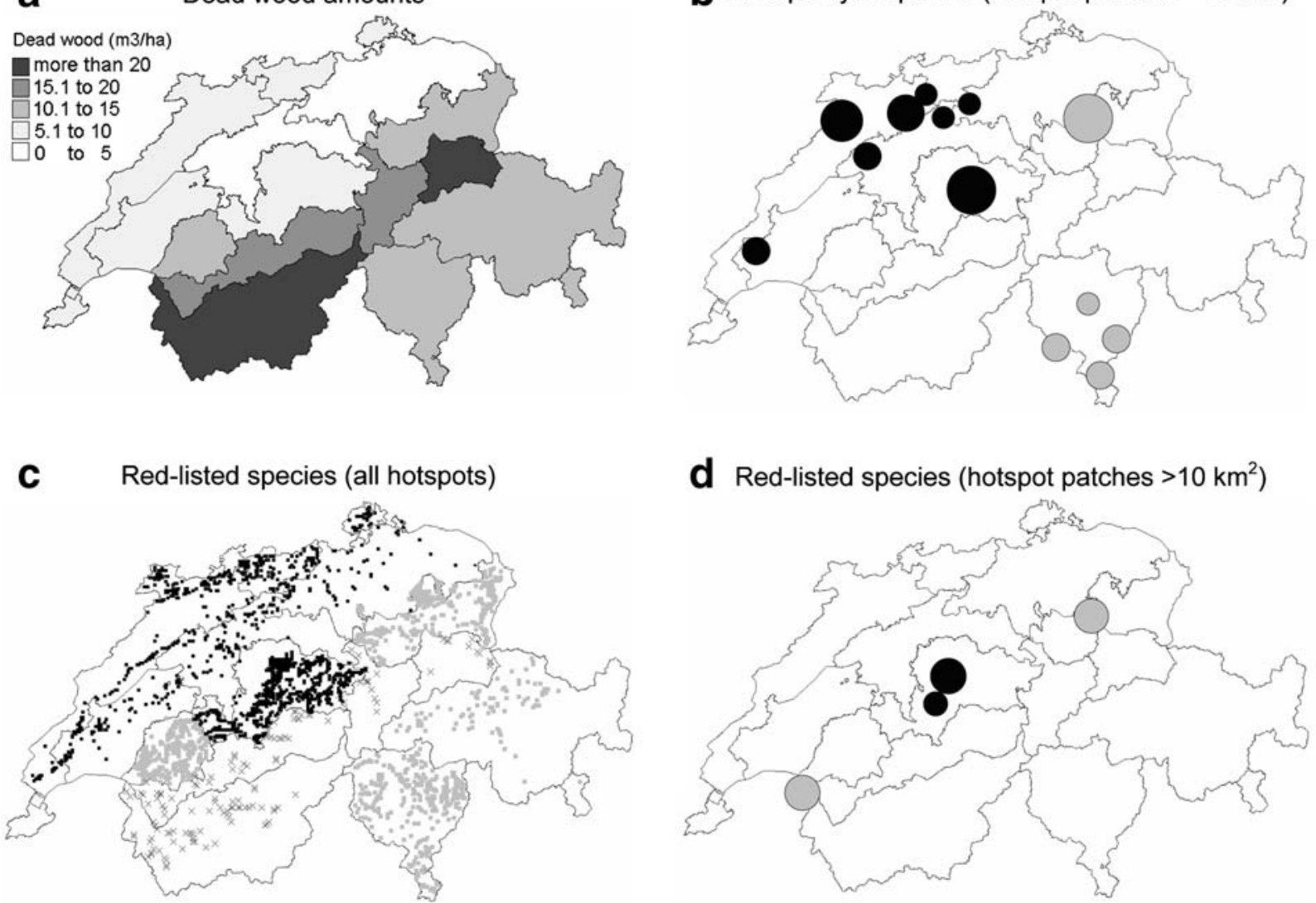

Fig. 2 a Dead-wood amounts in Switzerland. Units are economic regions after Brassel and Brändli (1999). b-d Potential hotspots and hotspot patches for two analyzed species groups. Dark circles/dots, intensive restoration efforts necessary $\left(<10 \mathrm{~m}^{3} \mathrm{ha}^{-1}\right.$ of dead wood);

\section{Priority Setting by Ranking Regions}

For priority setting, the five biogeographical regions were ranked from 1 to 5 with regard to their hotspot area of the different species groups. The region with the highest hotspot area ranked 1 , whereas the region with the lowest hotspot area ranked 5. This ranking was performed independently for results expressed as hectares and for results expressed as a percentage. A region may thus have, for example, rank 1 for hotspots expressed as hectares (largest total hotspot area in comparison to the other regions) but a low ranking for the hotspots expressed as a percentage (lower hotspot percentage than other regions compared to its whole forest surface).

\section{Conservation vs. Restoration}

In order to determine where to undertake conservation or restoration efforts, we overlaid the identified potential hotspots on a map of dead-wood amounts. Hotspots or hotspot patches located in regions with comparatively high

gray circles/dots, extensive restoration efforts necessary (10$15 \mathrm{~m}^{3} \mathrm{ha}^{-1}$ of dead wood); crosses, conservation efforts recommended ( $>15 \mathrm{~m}^{3} \mathrm{ha}^{-1}$ of dead wood). Dead-wood data from the Second Swiss National Forest Inventory

levels of dead wood (average volume, $\geq 15 \mathrm{~m}^{3}$ per hectare) will merit conservation actions to be implemented. In contrast, considerable restoration efforts are necessary for hotspots located in regions with low levels of dead wood (average volume, $<10 \mathrm{~m}^{3}$ per hectare), and smaller efforts where dead-wood levels are between 10 and $15 \mathrm{~m}^{3}$ per hectare. It must be noted that for demanding saproxylic species, higher dead-wood levels $\left(\geq 20 \mathrm{~m}^{3}\right.$ per hectare) would be necessary (Bütler and others 2006). For example, for the local persistence of three-toed woodpeckers Picoides tridactylus, $\geq 18 \mathrm{~m}^{3}$ per hectare of dead trees (standing only) would be necessary (Bütler and others 2004). Data on dead-wood amounts were provided by the Swiss National Forest Inventory (Brassel and Brändli 1999).

\section{Results}

Validation of the Species Prediction Models

The average Spearman correlation coefficient of the AAF curves (Boyce index) ranged between 0.5 and 0.96, with a 
median of 0.8 for each species (Appendix: Table 2). The lowest values were encountered for ubiquitous species occurring over a broad habitat range (e.g., Picus viridis), which is a common phenomenon observed for widely distributed species (Sattler and others 2007). However, the distribution models were still meaningful regarding the proportion of validation cells with a $\mathrm{HS} \geq 50 \%$. This value was at least $70 \%$ for the species with the lowest Boyce index. Furthermore, the area-adjusted frequency cross-validation always exhibited values $<1$ for the low-HS suitability bins and $>1$ for the high-HS bins. The predictive accuracy of the models can therefore be considered medium to very good.

\section{Hotspot(1/2 Richness) vs. Hotspot(2/3 Richness)}

For each biogeographical region, the hotspot area (as either hectares or percentages) was reduced to about half by moving from one definition of hotspot, namely, hotspot(1/2 richness), to hotspot(2/3 richness) (see Table 1$)$. However, considering all regions together, the region's ranking was the same for either hotspot( $1 / 2$ richness) or hotspot( $2 / 3$ richness) definition (Table 1; Wilcoxon matched-pairs test, $Z=0.12, P=0.90$, for hotspots expressed as hectares, and $Z=0.039, P=0.97$, for hotspots as percentages). Considering the five biogeographical regions separately, no significant differences between the two hotspot definitions could be determined.

\section{Hotspot Area}

\section{Hotspot Area as Hectares}

The Jura and the Central Plateau present the largest hotspot areas for most species groups (insects, fungi, thermophilous species, and species on broadleaves; Table 1). Hotspots of

Table 1 Ranking of the five biogeographical regions in Switzerland with respect to their hotspot areas, according to different species groups

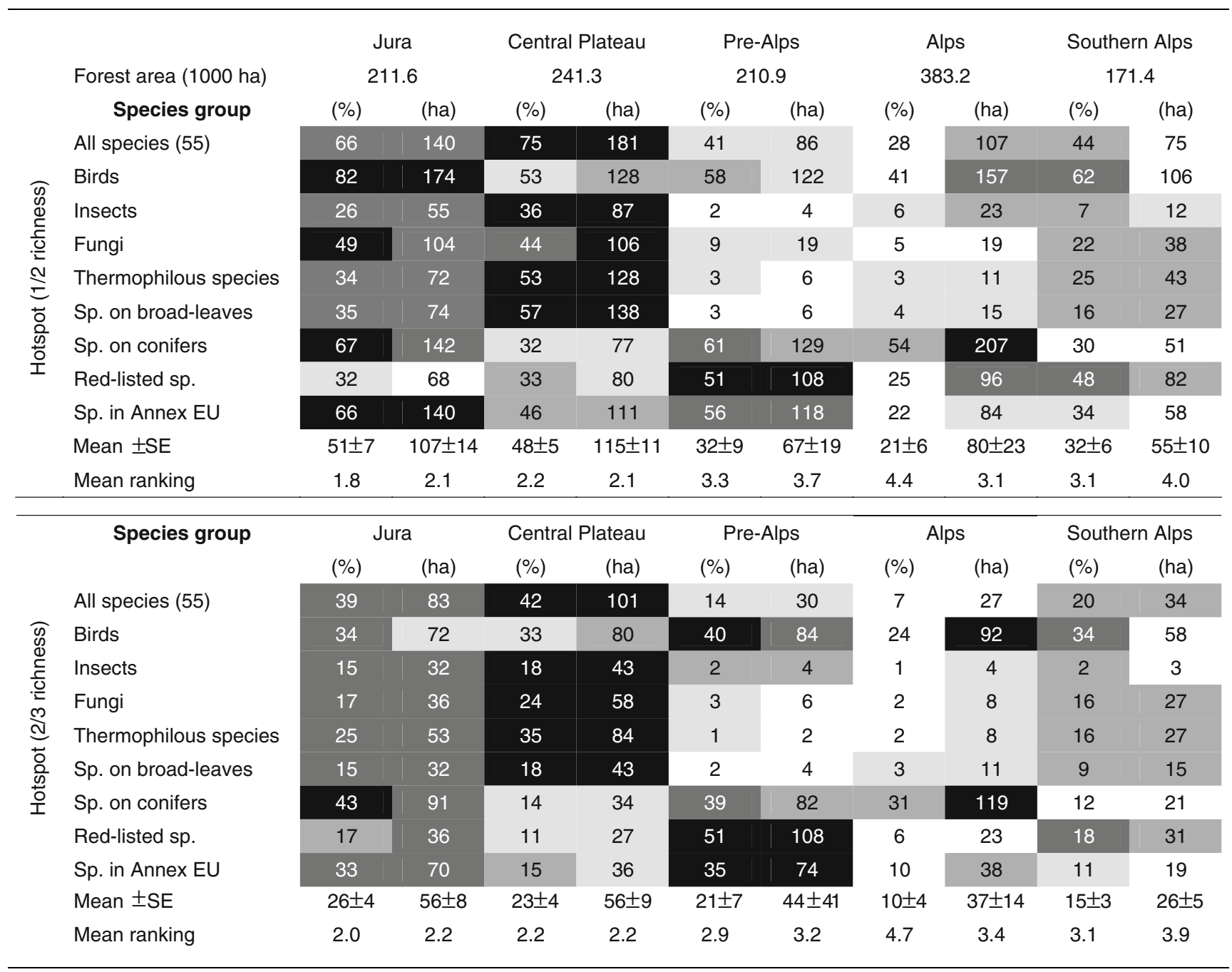

Note: Upper part: a hotspot is defined as containing at least one-half of the maximum regional species richness. Lower part: a hotspot contains at least two-thirds of the maximum species richness. Black = highest rank (1) to white = lowest rank (5). Values are given as percentages of the whole forest area in 1000 ha 
red-listed species and species in Annex EU are principally located in the Pre-Alps, whereas species living on conifers have most of their hotspots in the Alps, the Pre-Alps, and the Jura mountains. The largest hotspot area for birds was found in the Alps. Note that the Pre-Alps and the Alps showed a high variability in their ranking (from first to last rank). The Southern Alps contain only small hotspot areas for all species groups (ranks 3 to 5).

\section{Hotspot Area as a Percentage}

It is also interesting to consider the percentage of the forest area per region that contains hotspots. It may, for example, be possible that a region with a small forest area nevertheless has a high percentage of its forests containing hotspots. In this case, the region's forests would require species conservation attention. Therefore, we checked for differences in the rankings expressed as hectares versus percentages. When all regions were considered together, no differences were found (Wilcoxon matched-pairs test, $Z=0.17, P=0.86$, for hot$\operatorname{spot}(1 / 2$ richness), and $Z=0.26, P=0.79$, for hotspot( $2 / 3$ richness)). When the regions were analyzed separately, however, differences in ranking were found for hotspot $(1 / 2$ richness) in the Alps $(Z=2.37, P=0.018)$ versus the Southern Alps $(Z=2.20, P=0.028)$. In the Alps, species groups were comparatively better ranked by the hotspot area expressed as hectares, whereas in the Southern Alps, they achieved a higher ranking when the hotspot area was expressed as apercentage. This is due to substantial differences in the forest area, which is largest in the Alps (383,214 ha) and smallest in the Southern Alps (171,434 ha). The Jura and the Central Plateau are the regions with the highest percentages of hotspots for most species groups (Table 1). Similarly, the highest percentages for threatened species (red list and Annex EU) are found in the Pre-Alps. For birds, the Pre-Alps seem to have relatively more forests with hotspots than the Alps. In general, the lowest percentages for the selected saproxylic and old-growth species groups are found in the Alps. First ranks (dark cells) appear more often in the Jura, the Central Plateau and the Pre-Alps than in the other regions.

\section{Hotspot Patches}

As expected, the species group with all 55 species had the highest number of hotspot patches (Fig. 1). No hotspot patches could be detected with our method for insects, fungi, and species living on broadleaves. The Central Plateau and the Alps did not contain any hotspot patches for any species groups considered in this study. The two hotspot patches in the Pre-Alps (Napf, $1408 \mathrm{~m}$ a.s.l.; Schnebelhorn, $1292 \mathrm{~m}$ a.s.l.) contain five of the nine species groups (all species, birds, species living on coniferous, red-listed species, and species of the Annex EU).

\section{Conservation vs. Restoration}

Dead-wood amounts are not distributed homogeneously across Switzerland (Fig. 2a). The lowest levels are found on the Central Plateau $\left(\leq 5 \mathrm{~m}^{3}\right.$ per hectare), in the Jura Mountains, and in the central part of the Pre-Alps ( $\leq 10 \mathrm{~m}^{3}$ per hectare). In some regions of the Alps, however, average dead-wood amounts reach more than $20 \mathrm{~m}^{3}$ per hectare. It is worth noting that for the total species group (sum of the 55 analyzed saproxylic species), most potential hotspots are located in regions where dead-wood amounts are rather low (Figs. 1b and 2a). Considerable restoration efforts would be necessary to improve the dead-wood habitat in hotspot patches in the northwestern parts of Switzerland (Fig. 2b). Hotspot patches located in the Southern Alps and eastern Pre-Alps would require somewhat smaller efforts to restore the dead-wood habitat.

For red-listed species, hotspots and hotspot patches are mostly concentrated in the Pre-Alps (Fig. 2c and d), where restoration measures seem to be necessary. Only a few hotspots are located in regions with relatively high deadwood levels ( $>15-20 \mathrm{~m}^{3}$ per hectare), in particular, in the western part of the Alps.

\section{Discussion}

Does the Hotspot Definition Influence Priority Setting?

For objective priority setting, it is important to check to what extent the determined conservation/restoration priorities are sensitive to the adopted definition of a hotspot. In our hotspot definition, a cell is considered a hotspot if the number of overlaid species predicted in it is at least one-half or twothirds of the regional maximum species richness. The rankings based on the hotspot area in each biogeographical region, expressed either as hectares or as a percentage, were similar for both hotspot definitions (one-half and two-thirds richness). This observation underlines the robustness of our approach, regardless of whether the value of one-half or twothirds was used. However, the lower threshold above which a cell was included as a hotspot $(1 / 2 \times$ species richness $)$ led to more grid cells (in this study $1 \mathrm{~km}^{2}$ ) being included than with the higher threshold $(2 / 3 \times$ species richness). The hotspot areas in each biogeographical region were twice as high with the value one-half as with two-thirds. This demonstrates the hotspot area's sensitivity to the definition. Selecting the threshold of $2 / 3 \times$ species richness in our study indicated that an average proportion of $10 \%$ of the total Swiss forest surface potentially be designated conservation/restoration areas. This is in agreement with forest policy in Switzerland and with the recommendation of the World Conservation Union outlining that countries should establish a minimum conservation area of up to $10 \%$ 
of their total area (Soulé and Sanjayan 1998). Nevertheless, although politically expedient, the scientific basis and conservation value of such uniform targets based on percentage have been questioned.

\section{Species Groups and Hotspot Locations}

In this study, we considered relatively large taxonomic groups, e.g., birds, insects, and fungi. The locations of hotspots for such large groups are more likely to overlie than are those for fine-scale groups (e.g., groups at the level of the family) (Reid 1998). Nevertheless, the geographical locations of hotspots differed between the different species groups. For fungi and insects we noted similar regional priorities, with the highest ranking in the Jura and on the Plateau. However, different regional hotspot locations appeared for birds. Our findings support previous observations that there tends to be a lack of correspondence between the locations of hotspots of different species groups, especially if narrow-range or threatened species were studied (Balmford and Long 1995; Bonn and others 2002; Moore and others 2003). Furthermore, lack of correspondence between species hotspots in our study was registered not only between different taxa (birds, insects, and fungi), but also between different ecological and/or protection status species groups (e.g., thermophilous or red-listed species). Our observations demonstrate that the location of hotspots is sensitive to the selected species, even with the coarse taxonomic and geographical resolutions we used in this study. This implies that conservation priorities determined on the basis of a specific group cannot be relied on to capture similar patterns in other groups, as previously reported by Reid (1998).

Until now, the Federal Office for the Environment in Switzerland has considered the 'all species' group the main reference in order to establish guidelines for a national dead-wood species conservation strategy. Our study suggests that the Central Plateau and the Jura are potentially the most valuable regions for high saproxylic and oldgrowth species richness. These two regions were also highlighted for specific species groups (insects, fungi, thermophilous species, and species on broadleaves). Nevertheless, the species richness of birds, red-listed species, and species in Annex EU was found to be high in the mountain regions in Switzerland (in the Alps and PreAlps). Our observations underline the importance of carefully choosing the species or species groups to be considered in order to locate regions with the best conservation outcome. In a national context, Switzerland may give its national red-list species high conservation priority, whereas in a more international context, e.g., for the whole of Europe, species belonging to Annex EU or species living in the Alps may be worth being the focus of conservation efforts. In particular, some regions in the Swiss Alps may play an important role in conservation, as they contain socalled rarity hotspots. Switzerland, thus, is partly responsible for the conservation of many mountain species in Europe, in particular, species living on conifers.

Since regions with a high conservation value often do not correspond across different species groups or taxa, it is of prime importance that decision makers define a national biodiversity strategy prior to the implementation of conservation or restoration efforts. In Switzerland, a national biodiversity strategy, such as claimed by the Convention on Biological Diversity (CBD; Article 6; http://www.cbd.int/ convention/convention.shtml), has yet to be defined.

\section{Hotspot Patches}

Previous research suggests that a species has a greater likelihood of persisting in areas located adjacent to other populations of the same species (Kirby 1995; Buckley and Fraser 1998). Another aspect to be considered is that small fragments of remnant forest may be too small and isolated to be of much conservation value (Brooks and others 1999; Ferraz and others 2003). Small fragments should, therefore, receive lower priority for specific conservation efforts than larger, more connected areas (Harris and others 2005) unless special circumstances warrant their preservation, for example, if they are the last refuge of an endemic species or if they serve as a stepping stone to connect larger ones. Many cells identified as potential hotspots for saproxylic and oldgrowth species in Switzerland are isolated or agglomerated with only a few other hotspot cells ( $<50 \%$ of the cells within a circle radius of $5 \mathrm{~km}$ are hotspots). On the Central Plateau, an important proportion of the forest area contains potential hotspots. Many saproxylic species are expected to be found, if the dead-wood habitat quality is sufficient. However, anthropogenic pressure is elevated (settlements and urban areas made up $14.6 \%$ of the total area in 2001 [SFSO 2001]) and the remaining forest in this region is, as a result, extremely fragmented. Consequently, no hotspot patches could be located with our method on the Central Plateau.

In the other biogeographical regions of Switzerland, anthropogenic pressure is lower (settlements and urban areas in 2001 made up $7.4 \%$ of the total area in the Jura and $<4.5 \%$ in the mountain regions, i.e., in the Alps, Pre-Alps, and Southern Alps [SFSO 2001]). Forests in these regions are therefore less scattered, so that they contain larger areas that are potentially valuable for saproxylic and old-growth species. In the Jura, Pre-Alps, and Southern Alps, hotspot patches were found for several species groups including two hotspot patches in the Pre-Alps covering more than $100 \mathrm{~km}^{2}$ for five of the nine species groups. These two sites, which are situated in landscapes below $1400 \mathrm{~m}$ a.s.l. and are dominated by large continuous forests, merit special attention when selecting protected areas and implementing conservation strategies. 
Several of the hotspot patches identified in this study correspond to regions that had previously been suggested as possible candidates for large protected forest areas in Switzerland (Indermühle and others 1998).

The chosen approach of locating hotspot patches is a valuable complement to priority setting, since it takes into account both the size and the connectivity of the clustered hotspot cells. Note that compact structures with an ellipsoid shape tend to be more likely to act as patches than narrow and long clusters, because of the circular shape and size of the integration area (see methods).

\section{Implications for Ecosystem Management}

\section{Priority Setting}

We located potential hotspots of saproxylic and old-growth species of special concern in Switzerland that have been previously determined by experts. In our HS modeling, we deliberately excluded dead-wood amount as a variable explaining potential species distribution. As a result, we were able to distinguish either existing hotspots (where saproxylic species diversity is high and thus dead-wood amounts could also reach high levels) or potential hotspots (where species diversity potential is high, although dead wood may currently be a limiting factor). By comparing the resulting hotspot locations with a map of dead-wood amounts in Switzerland, four cases appear (Fig. 2): (i) regions with a high potential for focus species and a high dead-wood level; (ii) regions with a high potential for focus species but with a low dead-wood level; (iii) regions with a low potential for focus species, but with a high level of dead wood; and (iv) regions with a low potential for focus species and with a low dead-wood level.

In view of limited funding for biodiversity conservation in Switzerland, we suggest concentrating conservation efforts to regions of type $\mathrm{i}$ and undertaking restoration actions in regions of type ii. Regions of type iii merit some conservation efforts but no special financial subsidies. Finally, regions of type iv are of lowest interest for the conservation of saproxylic and old-growth species. It must be noted, however, that this approach of defining potential hotspots of diversity and possible conservation or restoration priorities remains typically a scientific top-down approach. In practice, the acceptance and the readiness of the local population and politics for species conservation are key players in such processes.

\section{Transfer to Other Regions or Ecosystems}

Species distribution models are increasingly applied for purposes of conservation planning and ecosystem management (Allouche and others 2008). ENFA is one of several methods in the literature for modeling HS when absence data are missing. It has a number of advantages over existing presence-data-only techniques (Tole 2006). In our case it revealed an appropriate tool to handle presence data only of species with poorly known distributions. Most of the recent (2005 and later) studies using ENFA with Biomapper have included only a small number of species (15 studies of 21 having only 1-3 species [but see, e.g., Soares and Brito 2007]). Our study, where 55 focal species were separately modeled and their HS maps then overlaid, demonstrated, however, that ENFA is also a valuable tool for the identification of species' hotspots (see also Tole 2006). We believe that a similar approach to ours may also be useful for setting conservation/restoration priorities in other ecosystem types (e.g., mountain areas or agricultural systems).

\section{Conclusion}

Overlaying predicted HS maps of numerous species (55 focal species in this study) appears to be an appropriate tool to locate potential biodiversity hotspots. This is particularly the case for species for which distribution is poorly known and absence data are lacking. In particular, for dead-wood dependent species, which often survive in suboptimal habitats, absence data may reflect factors that are unrelated to species presence, for example, degradation of habitat, i.e., a lack of dead wood. It is therefore preferable to use a method based on presence data only, if the aim is to identify regions where either conservation or restoration efforts are worth undertaking.

One of our findings was that potential hotspots are very sensitive to the species considered (for both taxonomic and focal species groups). The 'all species' approach (high species richness) may fail to conserve specific species groups. This implies that it is essential to define a biodiversity strategy with precise conservation objectives (e.g., species groups to be conserved in a national and international context), prior to implementing conservation or restoration efforts in specific regions. Identifying hotspot patches (i.e., connected hotspot cells) is a valuable complementary approach toward highlighting large areas with high concentrations of hotspots.

Acknowledgments This study was supported by the Federal Office for the Environment. We especially thank Professor Rodolphe Schlaepfer for his supervision during the project. The authors acknowledge the support of the Swiss Centre of Cartography of the Fauna, the Swiss Ornithological Institute, and the Swiss Federal Statistical Office. We would also like to thank Markus Bolliger, Urs-Beat Brändli, Peter Brassel, Sylvie Barbalat, François Claude, Philippe Clerc, Goran Dusej, Yves Gonzeth, Vincent Gorgerat, Kurt Grossenbacher, Peter Hahn, Alexandre Hirzel, Nicolas Kueffer, Pascal Moeschler, Pierre Mollet, Abram Pointet, Jörg Rüetschi, Thomas Sattler, Christoph Scheidegger, Hans Schmid, Benedikt Schmidt, Beatrice Senn-Irlet, Silvia Stofer, Junior Tremblay, Ulrich Ulmer, Beat Wermelinger, and Niklaus Zimmermann. The manuscript was substantially improved by the refereeing of Jean-Jacques Sauvain. 


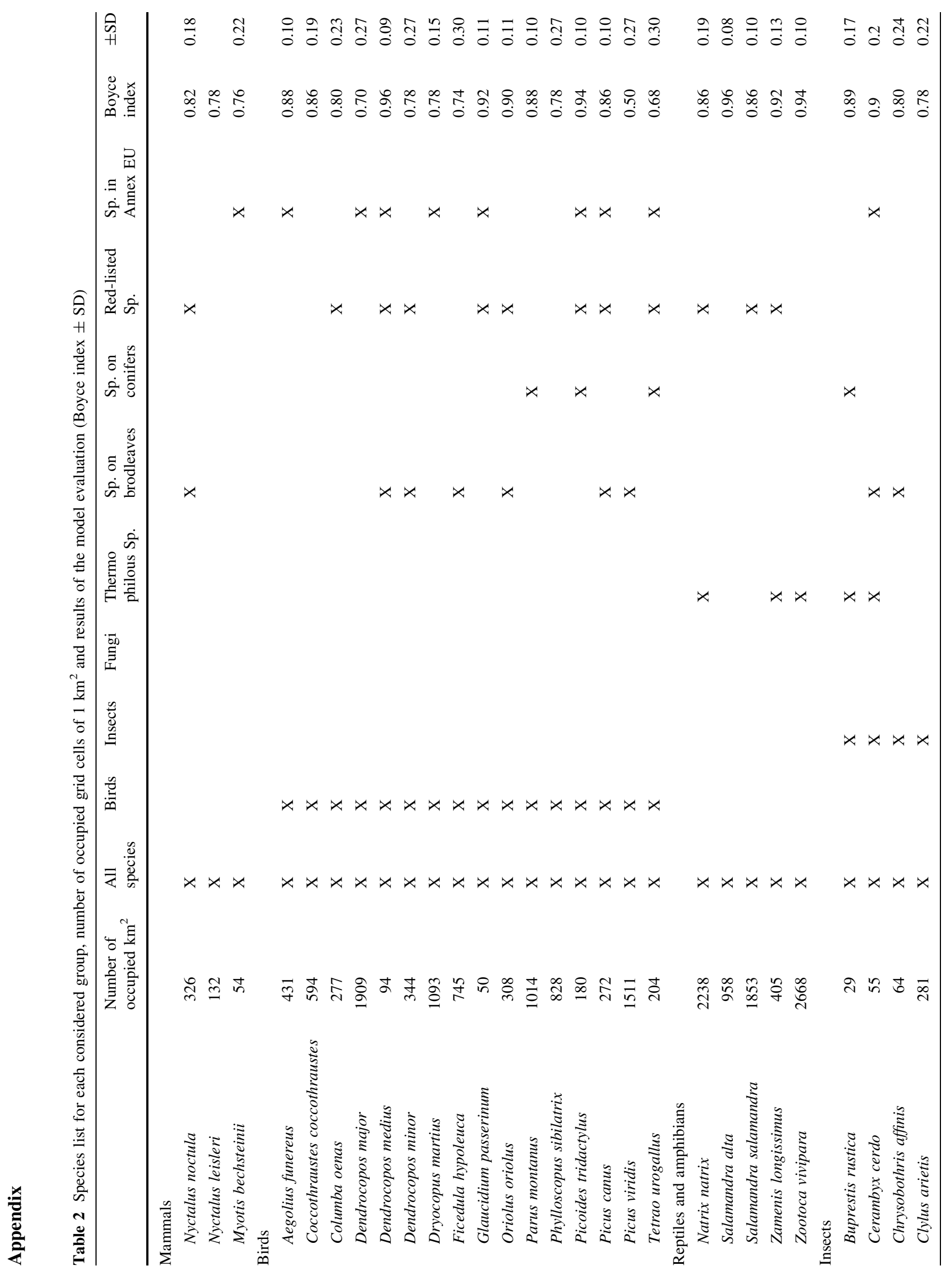


116

Environmental Management (2009) 44:105-118

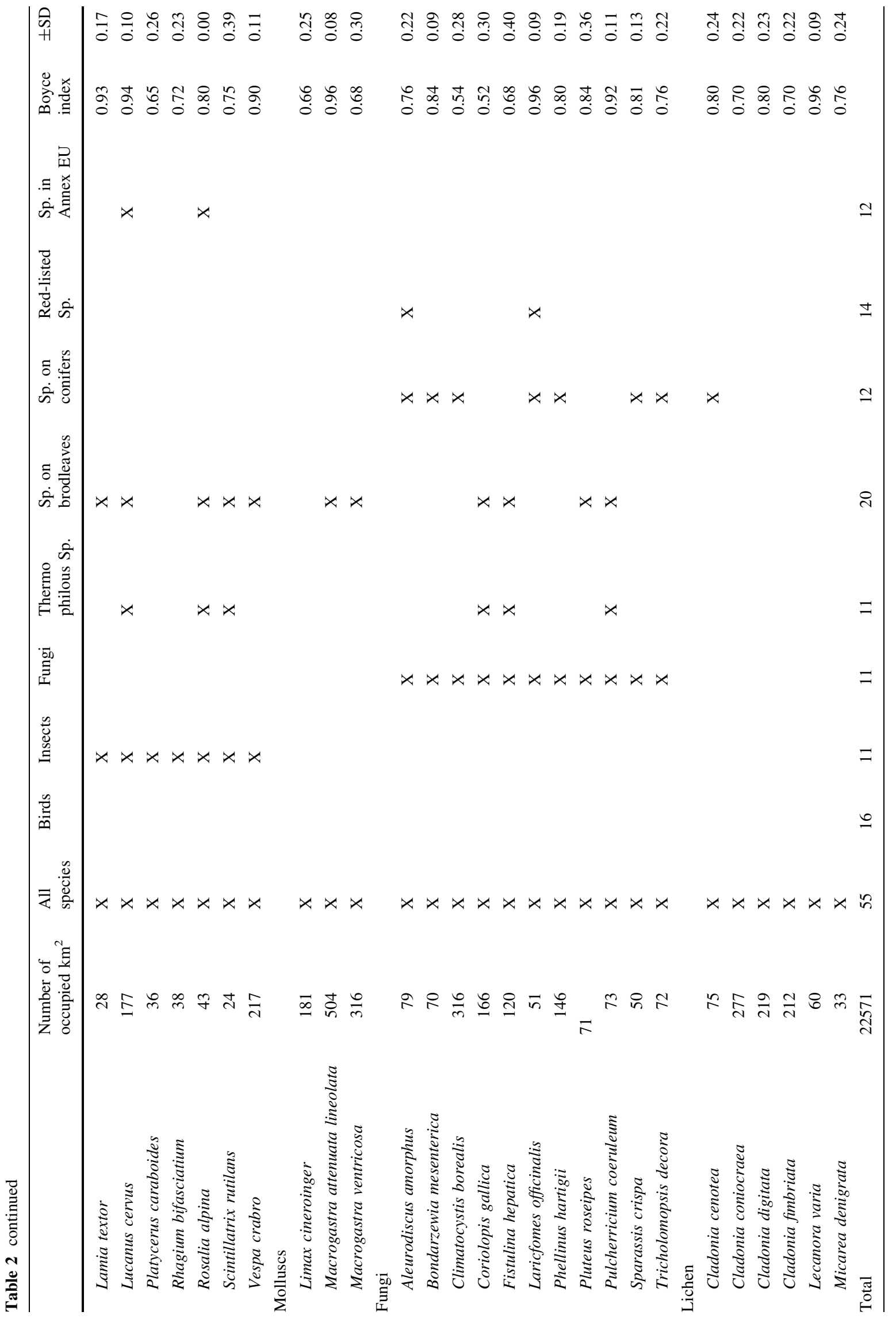

Springer 
Table 3 Ecogeographical variables used to model habitat suitability maps

\begin{tabular}{|c|c|c|}
\hline & Ecogeographical variable & Unit \\
\hline \multirow[t]{8}{*}{ Climate $^{\mathrm{a}}$} & Monthly moisture index & $1 / 10 \mathrm{~mm} / \mathrm{mth}$ \\
\hline & Number of precipitation days per growing season & nday \\
\hline & Monthly mean precipitation sum (1961-1990) & $1 / 10 \mathrm{~mm} / \mathrm{mth}$ \\
\hline & Annual average number of frost days during growing season & $1 / 100$ nday \\
\hline & Annual average site water balance & $1 / 10 \mathrm{~mm} / \mathrm{yr}$ \\
\hline & Monthly mean of average temperature (1961-1990): March & $1 / 10{ }^{\circ} \mathrm{C}$ \\
\hline & Monthly mean of average temperature (1961-1990): July & $1 / 10^{\circ} \mathrm{C}$ \\
\hline & Monthly mean of average temperature (1961-1990) & $1 / 10{ }^{\circ} \mathrm{C}$ \\
\hline \multirow[t]{5}{*}{ Forest $^{\mathrm{b}}$} & Forest border length & $\mathrm{m}$ \\
\hline & Surface of mixed broadleaf forest ( $10-50 \%$ coniferous) & $\mathrm{m}^{2}$ \\
\hline & Surface of broadleaf forest ( $0-10 \%$ coniferous) & $\mathrm{m}^{2}$ \\
\hline & Surface of mixed coniferous forest ( $50-90 \%$ coniferous) & $\mathrm{m}^{2}$ \\
\hline & Surface of coniferous forest ( $90-100 \%$ coniferous) & $\mathrm{m}^{2}$ \\
\hline Status $^{\mathrm{b}}$ & Surface of protected zones & ha \\
\hline \multirow[t]{6}{*}{ Topography $^{\mathrm{c}}$} & Altitude & $\mathrm{m}$ \\
\hline & Convexity & - \\
\hline & COSINUS of aspect & - \\
\hline & SINUS of aspect & - \\
\hline & Slope & $\circ$ \\
\hline & Standard deviation of altitude & - \\
\hline
\end{tabular}

${ }^{a}$ Bioclimatic maps (c) WSL based on Federal Office of Meteorology and Climatology, Meteoswiss (www.wsl.ch, www.meteoswiss.ch)

b Swiss Federal Statistical Office (www.bfs.admin.ch)

${ }^{c}$ LASIG, EPFL, from height model (http://lasig.epfl.ch/)

\section{References}

Allouche O, Steinitz O, Rotem D, Rosenfeld A, Kadmon R (2008) Incorporating distance constraints into species distribution models. Journal of Applied Ecology 45:599-609

Annex I (2003) Birds directive 79/409/EEC. http://ec.europa.eu/ comm/environment/nature/nature_conservation/eu_enlargement/ 2004/birds/annex_i.pdf

Annex II (2003) Habitat directive 92/43/EEC. http://europa.eu.int/ comm/environment/nature/nature_conservation/-eu_nature_legis lation/habitats_directive/index_en.htm

Araújo MB, Williams PH (2000) Selecting areas for species persistence using occurrence data. Biological Conservation 96: $331-345$

Ås S (1993) Are habitat islands islands? Woodliving beetles (Coleoptera) in deciduous forest fragments in boreal forest. Ecography 16:219-228

Balmford A, Long A (1995) Across-country analyses of biodiversity congruence and current conservation effort in the tropics. Conservation Biology 9:1539-1547

Begon M, Harper JL, Townsend CR (1996) Ecology: individuals, populations and communities. Blackwell Science, Oxford, UK

Bonn A, Rodrigues ASL, Gaston KJ (2002) Threatened and endemic species: are they good indicators of patterns of biodiversity on a national scale? Ecology Letters 5:733-741

Boyce MS, Vernier PR, Nielsen SE, Schmiegelow FKA (2002) Evaluating resource selection functions. Ecological Modelling 157:281-300

Brassel P, Brändli UB (1999) Schweizerisches Landesforstinventar. Ergebnisse der Zweitaufnahme 1993-1995. Birmensdorf,
Eidgenössische Forschungsanstalt für Wald, Schnee und Landschaft. Bern, Bundesamt für Umwelt, Wald und Landschaft. Bern, Stuttgart, Wien, Haupt

Brooks TM, Stuart LP, Oyugi JO (1999) Time lag between deforestation and bird extinction in tropical forest fragments. Conservation Biology 13:1140-1150

Buckley GP, Fraser S (1998) Locating new lowland woods. English Nature Research Report 283. English Nature, Peterborough, UK

Bütler R, Angelstam P, Schlaepfer R (2004) Quantitative snag targets for the three-toed woodpecker, Picoides tridactylus. Ecological Bulletins 51:219-232

Bütler R, Lachat T, Schlaepfer R (2006) Saproxylische Arten in der Schweiz: ökologisches Potenzial und Hotspots. Schweizerische Zeitschrift für Forstwesen 157:208-216

Ferraz G, Russell GJ, Stouffer PC, Bierregaard RO, Pimm SL, Lovejoy TE (2003) Rates of species loss from Amazonian forest fragments. Proceedings of the National Academy of Science 100:14069-14073

Ferrier S, Guisan A (2006) Spatial modelling of biodiversity at the community level. Journal of Applied Ecology 43:393-404

Fielding AH, Bell JF (1997) A review of methods for the assessment of prediction errors in conservation presence/absence models. Foundation for Environmental Conservation 21:38-49

Gaston K (2000) Global patterns in biodiversity. Nature 405:220-227

Gjerde I, Saetersdal M, Rolstad J, Blom HH, Storaunet KO (2004) Fine-scale diversity and rarity hotspots in northern forests. Conservation Biology 18:1032-1042

Grove SJ (2002) Saproxylic insects ecology and the sustainable management of forests. Annual Review of Ecological Systems $33: 1-23$ 
Guisan A, Theurillat JP (2000) Equilibrium modeling of alpine plant distribution and climate change: How far can we go? Phytocoenologia 30:353-384

Guisan A, Zimmermann NE (2000) Predictive habitat distribution models in ecology. Ecological Modelling 135:147-186

Harris GM, Jenkins CN, Pimm SL (2005) Refining biodiversity conservation priorities. Conservation Biology 19:1957-1968

Hirzel AH, Hausser J, Chessel D, Perrin N (2002) Ecological-niche factor analysis: How to compute habitat-suitability maps without absence data? Ecology 83:227-236

Hirzel AH, Le Lay G, Helfer V, Randin C, Guisan A (2006) Evaluating the ability of habitat suitability models to predict species presences. Ecological Modelling 199:142-152

Hutchinson GE (1957) Concluding remarks. In: Harbour symposium on quantitative biology, pp 415-427

Indermühle M, Kaufmann G, Steiger P (1998) Konzept Waldreservate Schweiz. Schlussbericht des Projektes Reservatspolitik der Eidgenössischen Forstdirektion. Unpublished report

Jaarsveld AS, Freitag S, Chown SL, Müller C, Koch S, Hull H, Bellamy C, Krüger M, Endrödy-Younga S, Mansell MW, Scholtz CH (1998) Biodiversity assessment and conservation strategies. Science 279:2106-2108

Kirby K (1995) Rebuilding the English countryside: habitat fragmentation and wildlife corridors as issues in practical conservation. English Nature Science No. 10. English Nature, Peterborough, UK

Köhler F (2000) Totholzkäfer in Naturwaldzellen des nördlichen Rheinlandes. Vergleichende Studien zur Totholzkäferfauna Deutschlands und deutschen Naturwaldforschung [Saproxylic beetles in nature forests of the northern Rhineland. Comparative studies on the saproxylic beetles of Germany and contributions to German nature forest research]. Schrr. LÖBF/LAfAO NRW (Recklinghausen) 18:1-351

Komonen A, Penttilä R, Lindgren M, Hanski I (2000) Forest fragmentation truncates a food chain based on an old-growth forest bracket fungus. Oikos 90:119-126

Korpel S (1995) Die Urwälder der Westkarpaten. Gustav Fischer Verlag, Stuttgart

Lambeck RJ (1997) Focal species: a multi-species umbrella for nature conservation. Conservation Biology 11:849-856

Lehmann A, Leathwick JRJ, McC Overton (2002) Assessing biodiversity from spatial predictions of species assemblages: a case study of New Zealand ferns. Ecological Modelling 157:261-280

Margules CR, Pressey RL (2000) Systematic conservation planning. Nature 405:243-253

Moore JL, Balmford A, Brooks T, Burgess N, Hansen LA, Rahbek C, Williams PH (2003) Performance of sub-Saharan vertebrates as indicator groups for identifying priority areas for conservation. Conservation Biology 17:207-218

Myers N (1988) Threatened biotas: "hotspots" in tropical forests. Environmentalist 8:187-208

Myers N, Mittermeier RA, Mittermeier CG, da Fonseca GAB, Kent J (2000) Biodiversity hotspots for conservation priorities. Nature 403:853-858

Parker SP (1982) Synopsis and classification of living organisms. McGraw-Hill, New York

Prendergast JR, Quinn RM, Lawton JH, Eversham BC, Gibbons DW (1993) Rare species, the coincidence of diversity hotspots and conservation strategies. Nature 365:335-337

Reid WV (1998) Biodiversity hotspots. TREE 13:275-280

Reutter BA, Helfer V, Hirzel AH, Vogel P (2003) Modelling habitat suitability using museum collections: an example with three sympatric Apodemus species from the Alps. Journal of Biogeography 30:581-590

Roberts CM, McClean CJ, Veron JEN, Hawkins JP, Allen GR, McAllister DE, Mittermeier CG, Schueler FW, Spalding M, Wells F, Vynne C, Werner TB (2002) Marine biodiversity hotspots and conservation priorities for tropical reefs. Science 295:1280-1284

SAEFL (1999) The Swiss forest-taking stock. Interpretation of the second national forest inventory in terms of forestry policy. Swiss Agency for the Environment Forests and Landscape, Bern

Sattler T, Bontadina F, Hirzel A, Arlettaz R (2007) Ecological niche modelling of two cryptic bat species calls for a reassessment of their conservation status. Journal of Applied Ecology 44:11881199

SFSO (2001) The changing face of land use: land use statistics of Switzerland. Swiss Federal Statistical Office, Neuchâtel

SNFP (2003) Swiss national forest programme. http://www.umweltschweiz.ch/buwal/eng/fachgebiete/fg_wald/rubrik3/uebersicht/ projekt_wap/index.html

Soares C, Brito JC (2007) Environmental correlates for species richness among amphibians and reptiles in a climate transition area. Biodiversity and Conservation 16:1087-1102

Sokal RR, Rohlf FJ (1981) Biometry: the principles and practice of statistics in biological research. W. H. Freeman, New York

Soulé ME, Sanjayan MA (1998) Conservation targets: Do they help? Science 279:2060-2061

Tardif B, DesGranges JL (1998) Correspondence between bird and plant hotspots of the St Lawrence River and influence of scale on their location. Biological Conservation 84:53-63

Tole L (2006) Choosing reserve sites probabilistically: a Colombian Amazon case study. Ecological Modelling 194:344-356 